\title{
Research on the Method of Integrating Humanistic Literacy in Professional Courses
}

\author{
Jukun Yao ${ }^{1, a}$, Peizhi Cui ${ }^{1, b,{ }^{*}}$ and Junwei Yang ${ }^{1, c}$ \\ ${ }^{1}$ Department of Equipment Support and Remanufacturing, Army Armored Forces Academy, Beijing, \\ China \\ ayaojukun@163.com, b 1821510346@qq.com, c101247234@qq.com \\ *Yao Jukun
}

Keywords: Humanistic quality, Teaching mode, Teachers, Professional courses.

\begin{abstract}
The rapid development of society has put forward higher requirements for college students' humanistic literacy, but limited to the limited hours of humanistic courses in engineering colleges, it is of great significance to develop the integration of humanistic literacy in professional courses. Based on the analysis of the connotation of humanistic quality, this paper constructs the knowledge system of humanistic quality in college professional courses, puts forward the teaching method of "the unity of knowledge and practice" in professional courses, and establishes an educational model that follows the combination of "in-class and out-of-class", "preaching and teaching by example", "science and humanities", which provides a significant improvement of the effect of humanistic permeation education.
\end{abstract}

\section{专业课中人文素养融合培养方法研究}

姚巨坤 ${ }^{1, a}$, 崔培枝 ${ }^{1, b}{ }^{*}$, 杨军伟 ${ }^{1, c}$

1陆军装甲兵学院装备保障与再制造系, 丰台, 北京, 中国

ayaojukun@163.com, b 1821510346@qq.com, c101247234@qq.com

*姚巨坤

关键词:人文素质; 教学模式; 教员队伍; 专业课程

中文摘要. 社会的快速发展对大学生的人文素养提出了更高要求, 但限于工程专业院校人文 课程学时有限, 开展专业课程中的人文素养融合培养具有重要意义。本文在分析人文素质内 涵的基础上，构建了专业课程中的人文素养知识体系，提出了在专业课程中 “知行合一” 的 人文素养渗透教学方法, 建立遵循 “课内与课外”、“言传与身教”、“科学与人文” 三结 合的教育模式，为显著提升人文渗透教育效果提供了方法。

\section{1. 引言}

大学教育培养的根本是人的培养。因此, 进行人文素质教育, 不仅是人文类课程的任务, 也是专业类课程的立足点和目标。研究专业课程中进行人文素质融合的教学方法与模式，是 促进工程专业院校大学生人文素质提升的重要手段。 


\section{2. 人文素质的内涵}

人文素质是建立在对一定人文知识拥有和内化基础上所形成的个人学识和修养，体现人 们在人文方面所具有的综合品质或达到的发展程度, 反映一个人的人格、气质、情感、精神、 世界观、人生观、价值观等方面的个性内在品质。

人文素质教育是指通过人文知识的传授、校园环境的熏陶以及学员自身的人文体验和实 践, 将人类优秀文化成果内化为学生永恒的精神、人格、气质、修养和行为的教育。

工程专业院校学员由于在课程设置中专业类课时较多，人文类课程课时相对较少，无法 完全满足学生未来发展中人文素质培养的需求。然而, 专业课程的科学技术中充满着历史、 哲学、文学、艺术等人文因素和人文精神, 通过合理的教学设计, 可以在进行专业课程传授 科技知识的同时, 实现人文精神的融合, 使专业课程丰满有魂, 使人文素质教育更形象生动, 促进学员不仅得到具体的科学知识, 还能受到高尚的人文精神与道德情操的熏陶 ${ }^{[1]}$ 。所以, 在专业课程教学中进行人文素质培养的融合教学完全是可行的方式, 也是在当前条件下有效 提升工程院校学生人文素质的必要手段。

\section{3. 专业课程中的人文素质内容体系}

专业课程中的人文素质培养融合可以从人文知识、人文精神、人文行为三个层次循序渐 进进行，可建立如表1所示的人文素质培养内容体系。

表1 专业课程中的人文素质内容体系

\begin{tabular}{|c|c|c|c|}
\hline \multirow{12}{*}{$\begin{array}{c}\text { 专业课 } \\
\text { 程中的 } \\
\text { 人文素 } \\
\text { 质内容 } \\
\text { 体系 }\end{array}$} & \multirow{5}{*}{$\begin{array}{l}\text { 专业课 } \\
\text { 中的人 } \\
\text { 文知识 }\end{array}$} & 历史 & 专业的技术发展史、设备发展史、历史人物典故、发展趋势等 \\
\hline & & 文学 & 相关专业知识的诗词、名言、名句、文章等 \\
\hline & & 哲学 & 专业发展中体现的技术认识论、方法论、辩证法、发展观等 \\
\hline & & 美学 & 与专业相关的知识美、机械美、技术美、逻辑美、规则美、色彩美等 \\
\hline & & 艺术 & 与专业相关的艺术形式, 如以专业知识为题的书法、篆刻、摄影等 \\
\hline & \multirow{4}{*}{$\begin{array}{l}\text { 专业课 } \\
\text { 中的人 } \\
\text { 文精神 }\end{array}$} & 品格 & 专业涉及人物或知识中展现出的坚强、勤奋、善良、正直、诚实等品格 \\
\hline & & 思维 & $\begin{array}{c}\text { 专业知识中运用的逻辑思维、系统思维、逆向思维、发散思维、均衡思维、 } \\
\text { 收玫思维、整合思维等思维方法 }\end{array}$ \\
\hline & & 团队 & 专业中所体现出的协作、团结、互助、友爱等团队精神 \\
\hline & & 责任 & 专业引申出的热爱国家、奋发进取、献身事业等使命感 \\
\hline & \multirow{3}{*}{$\begin{array}{l}\text { 专业课 } \\
\text { 中的人 } \\
\text { 文行为 }\end{array}$} & 言语 & 教员与学员在专业课程中的语言表现 \\
\hline & & 行为 & 教员与学员在专业课程中的行为表现。 \\
\hline & & 环境 & 专业教学所呈现的环境, 如教室、多媒体等 \\
\hline
\end{tabular}

人文知识包括文学、历史、哲学、美学等人文科学知识、艺术知识、自然学科知识等, 是人文素质形成和提高的基础。具体来讲, 主要包括与专业课程相关的文学内容(诗词、名言、 文章、著作)、历史(专业知识的发展史、专业名人、专业故事)、哲学(专业涉及的思维、方法)、 艺术(涉及专业内容的艺术形式，如书法、美术、篆刻、图片)等，这些人文知识的运用讲授， 可以提升教学效果, 加强人文素质融合 ${ }^{[2]}$ 。

人文精神是由人类优秀文化积淀、凝聚、孕育，并通过环境熏陶、实践锻炼内化于主体 的精神品格, 是内化于心的人性和人的本质的展现, 是人文素质对个性内心的追求。例如人 的高尚品格、爱国情操、奉献敬业等精神层面的所化于心的本质境界。学生人文精神培养就 是要培养关爱他人的品质和互助合作精神, 培养学员对国家的责任感和使命感, 培养学员高 雅的审美情趣。

人文行为是基于人文知识的积累和内化, 在人的行为中所表现的素养, 是人文精神的外 化表现和发展目标。例如, 专业课程中教员的言传身教, 学员的行动表现等, 都可以以一定 
的行为展示出来, 这是人文精神的外在体现。人文素质教育的目的是形成良好的人文行为, 真正影响其今后的工作与研究、生活与创造。

总之，人文教育的核心是“传道”。教师在“授业”、“解惑”之外，重要的是“传道”，即教给 学员做人的道理, 其中人文知识是知“道”于脑, 人文精神是化“道”于心, 人文行为是显“道” 于体。通过人文教育培养, 就是要实现学员由“知道为智”的人文知识向“体道为德”的人文行 为的转变, 实现人文素养的“知行合一”。

\section{4. “知行合一”的人文素质融合教学方法}

\section{1 源于历史一在专业知识中融合人文知识}

在专业知识讲解中, 可以对蕴含的历史等人文知识进行介绍, 从而引起学员学习的兴趣, 扩展学员的人文知识。例如, 在讲解刀具时, 可以通过中国历史博物馆展览的新石器时代的 石刀, 引起大家对刀具历史的理解，拓展刀具的历史概念; 在讲解磨削时, 可以引用“只要功 夫深、铁棒磨成针”、“宝剑锋从磨研出, 梅花香自苦寒来”等名句, 既能够通俗易懂的介绍磨 削的历史和加工方法, 又能够引申提出学员要敢于磨砺自己的品质; 在引出不同的机械加工 方法时，可以引用诗经《尔雅》篇的“骨谓之切，象谓之磋，玉谓之珧，石谓之磨”诗句，培 养大家对优秀传统文化的兴趣。

\section{2 成于思索一在专业课程中培养人文精神}

在课堂教学中，高水平的教员不仅传授给学员科学和人文知识，更要善于引导学员进行 人文思考, 使学员从内心深处产生自觉的人文向往和追求, 自觉地进行正确的人文价值选择 和取舍, 从而, 在更深的层面上树立起对他人、单位和国家的高度责任感和强烈的使命感 ${ }^{[3]}$ 。 教员要善于从专业知识引申出优秀思维方法和品质精神, 促进学员人文精神的提升。例如, 在讲解刀具材料的高速钢时, 可以讲解高速钢是由美国的两个工程师经过反复试验后发明的, 而这种高速钢的发明影响了机械加工一百年的历史，展示科学探索、发明创造精神，为社会 贡献价值。教员在讲解科学概念、原理、方法时, 一定会提到发现科学规律的动机, 提到科 学家如何通过艰苦的努力甚至牺牲生命取得创新, 以及这些成果的应用对社会可能造成的影 响等, 教员还会以自己的认识、情感、体会去影响学员, 实现对学员的正确人文与科学教育。

\section{3 达于现实一在专业教学中展示人文行为}

事实上，讲授任何专业课的教员，即使是无意识的，实际上也在进行着人文和科学的感 染, 能够通过展示在课堂上表现出的人文行为来直接影响和提升学员的人文素质。例如, 教 员可以通过自己干净整洁的仪容来展示良好的人文形象, 通过自己严谨的专业知识授课语言 来影响学员, 通过自己良好的言谈举止可以直接引导学员学习模仿。同时, 学员中也存在着 大量优秀的人文行为，例如学员之间的团结互助、勤奋学习、服从命令等，这都是表现出来 的优秀人文素质, 教员可以适时点评, 促进学员对优秀人文行为的了解认识, 提升学员追求 正确的世界观和价值观。

\section{5. 专业课堂人文素质融合的教育模式}

专业课中人文素质融合要遵循以人为本的基本原则，坚持“课内与课外相结合、言传与身 教相结合、科学知识与人文素质相结合”的“知行合一”培育模式。

\section{1 课内与课外相结合}

专业知识中的人文素质融合，不但要注重课内的人文知识融合和人文精神培养，还要注 重与课外的专业实践相结合。例如, 结合学员人文素质中创新思维方法的培养, 我们结合专 业课程教学内容知识, 开展了节能减排创新方案大赛。通过引导学员开展创新方案设计, 实 现了专业课程内容与工程创新思维方法的结合, 提升了学员的创新思维水平; 为了创造专业 
知识与人文素质结合氛围，我们将用电子显微镜等高端仪器设备拍摄的部分专业照片配上合 适的诗词, 制作成展板在单位墙壁上悬挂, 促进了大家对专业知识中美的认识。通过课内与 课外专业知识中人文素质的融合, 帮助学员形成一定的人生观、价值观, 道德观、审美观。

\section{2 言传与身教相结合}

言传与身教是开展教育的基本要求，教员自己的言行举止、礼仪规范等都对学员人文精 神的培养有着潜移默化的影响, 也是一种比较直观的、并可得到较好教育效果的方法。所以, 教员要能够通过对专业的提炼, 利用言语引导大家去学习专业课中的人文知识, 并不断加强 自己的人文修养，树立优秀的人文精神，展示良好的人文行为，通过言行来培养大家的人文 素质。另一方面, 教员还要严格要求自己, “其身正, 不令而行; 其身不正, 虽令不从。”要 注意在各种场合的行为举止, 以身作则, 展现美好的人文素质, 增加个人的人格鬼力, 真正 达到“学为人师, 行为世范”的标准。

\section{3 科学与人文相结合}

科学和人文是人类在实践中创造出来的最为宝贵的两种财富。科学追求的是真, 强调客 观规律, 给人以理性; 人文追求的是善, 有深厚的情感鬼力, 给人以悟性。科学精神和人文 精神是人类在认识与改造自然、认识与改造自我的活动中形成的一系列观念、方法和价值体 系。因此, 要在专业知识中实现两者的融合, 促进学员人文素质的提高。例如, 通过讲述与 教科书中科学家相关的故事, 让学员从中感知科学家的内心世界, 了解科学探索需要的方法, 需要的“甘于寂寞、勇于奋斗”的上下求索精神, 了解科学工作者的勤于思考、善于思考、治 学严谨、开放创新的科学精神, 理解科学发展的真正目标是为人类造福。也让学员能了解人 与自然的关系, 如何开发资源、能源, 如何改造世界, 又如何合理地利用资源, 具有能源的 知识、环保的知识、人口研究方面的知识等等, 了解如何建设一个可持续发展的世界所需要 的基本内容，充实科学人文内涵。

\section{6. 结论}

大学教育培养的根本是人的培养。理工类学员面临着专业类课时较多, 内容较为枯燥, 而人文课时相对较少, 无法满足学员人文素质培养的需求。然而, 专业课程的科学技术中充 满着历史、哲学、文学、艺术等人文因素和人文精神, 在进行专业课程传授科技知识的同时, 实现人文精神的融合, 不但使课程丰满有魂, 而且使人文素质教育更形象生动, 使学员不仅 得到具体的物质的科学知识, 而且受到高尚的人文精神与道德情操的熏陶。在专业课程中进 行人文素养教育需要遵循 “知行合一”的人文素质融合教育方法和融合原则, 遵循“课内与课 外”、“言传与身教”、“科学与人文”三结合的教育模式，提升人文融合教育效果。

\section{References}

[1] G. C. Chen, Y. C. Wan and Yulin Wang. Research and Practice of Integrating Humanistic Quality Education in Professional Course Teaching. Researches in Higher Education of Engineering, vol.s,pp69-71,2005

[2] L. K. Song. Humanistic Quality Education in Professional Course Teaching. Education of Chinese Medicine, vol.3, pp.68-70,2007

[3] T. X. Xue, Q. S. Pang. On the Integration of Humanities Education and Science Education in Universities. China Higher Education Research, vol.1,pp.16-19,2003 